\title{
ABO blood groups, Rhesus factor, and anaphylactic reactions due to Hymenoptera stings
}

\author{
Krzysztof Pałgan', Zbigniew Bartuzi', Elżbieta Chrzaniecka' \\ 1 Department of Allergology, Clinical Immunology and Internal Diseases, L. Rydygier Collegium Medicum, Bydgoszcz, \\ Poland
}

Pałgan K, Bartuzi K, Chrzaniecka E. ABO blood groups, Rhesus factor, and anaphylactic reactions due to Hymenoptera stings. Ann Agric Environ Med. 2017; 428-430. doi: 10.26444/aaem/74424

\begin{abstract}
Introduction. Numerous publications indicate that the prevalence of some infectious, neoplastic and immunological diseases are associated with $\mathrm{ABO}$ blood groups.

Objective. The aim of this study was to verify whether $A B O$ and Rh blood groups are associated with severe anaphylactic reactions after Hymenoptera stings.

Materials and Method. A study was undertaken of 71,441 Caucasian subjects living in the same geographic area. The study group included 353 patients with diagnosed systemic anaphylaxis to Hymenoptera venom. Control group included 71,088 healthy blood donors. Frequencies of $\mathrm{ABO}$ and Rhesus groups in the study and control groups were compared using univariate and multivariate analyses.

Results. No statistically significant interactions were observed between the ABO blood group and anaphylactic reactions to Hymenoptera.
\end{abstract}

\section{Key words}

Hymenoptera sting, anaphylaxis, ABO blood group, Rh factor

\section{INTRODUCTION}

The prevalence of systemic hypersensitivity reactions to Hymenoptera stings is estimated to occur among adults ranging from $0.3 \%-7.5 \%$ of the general population [1] The Apidae and Vespidae are responsible for the allergic reactions. Bees and wasps stings can lead to local or systemic reactions. There are several risk factors for a severe reaction to a hymenoptera sting. History of a prior severe sting reaction, occupation, leisure activity, residence, age and gender have been described as influencing the exposure risk [2, 3, 4].

The ABO blood group system was discovered in 1900 by Karl Landsteiner who was consequently awarded the Nobel Prize. The antigens of the group are glycoproteins expressed on the surface of red blood cells and several other tissue, including epithelial cells of the gastrointestinal, respiratory, and reproductive tracts, as well as in salivary glands and skin [5].

Numerous studies conducted several decades ago suggested a link between inherited human blood group antigens and the risk of various diseases, including such malignancies as gastric cancer, pancreatic cancer, lung cancer, and other infectious and non-infectious diseases $[5,6]$.

The aim of this study was to investigate the relationship between $\mathrm{ABO}$ and Rhesus factor blood types and anaphylactic reactions after hymenoptera sting.

\footnotetext{
Address for correspondence: Krzysztof Pałgan, MD, Collegium Medicum, Nicolaus Copernicus University, Bydgoszcz, Poland

Department of Allergology, Clinical Immunology and Internal Diseases, Ujejskiego 75, 85-168 Bydgoszcz, Poland

E-mail: palgank@wp.pl

Received: 15 January 2015; accepted: 22 March; first published: June 2017
}

\section{MATERIALS AND METHOD}

353 of both genders were included in the study. The patients with a serologically determined as belonging to the A, B, $\mathrm{AB}$ and 0 blood groups, $\mathrm{Rh}$ factor and classified systemic reaction grade III and IV according to Ring and Messmer [7] were enrolled in the study. The diagnosis of hymenoptera venom allergy were established based on patient history, intradermal skin tests, and the levels of serum-specific IgE to major venom allergen.

The distributions of anaphylactic patients after hymenoptera stings were compared with the distribution of blood groups of healthy donors. The controls were taken from healthy people who visited the blood bank of the Regional Centre for Blood Transfusion in Bydgoszcz, Poland. A total of 71,088 healthy adults over the age of 18 were approached. Physicians interviewed the potential donors before the blood donation. During face-to-face interviews, a physician collected information on the presence of infectious diseases, acute and chronic allergological diseases, all anaphylaxis in the past, and risk factors for blood-transmissible diseases. In addition, height, weight, blood pressure, and body temperature were measured. Only individuals without a history of hymenoptera venom anaphylaxis and the above mentioned diseases or risk factors for blood-transmissible diseases were allowed to donate blood.

The Caucasian patients and controls enrolled in the study came from the central part of Poland.

Statistical analysis was performed using the exact Pearson's chi-squared test. P-values $<0.05$ were considered statistically significant. 


\section{RESULTS}

The mean age of 353 patients was $45 \pm 3.74$ years. The 2 groups consisting of patients with systemic anaphylaxis to Vaspides or Apides venom were compared with control healthy blood donors. The results showed that among all participants sensitized to hymenoptera venom, 127 patients (35.98\%) had A group, 82 patients (23.23\%) - B group, 28 patients (7.93\%) - AB group, and 116 patients (32.86) - 0 group. Among all patients sensitized to hymenoptera venom, 271 subjects (76.77\%) displayed systemic reactions after wasp sting and 82 patients $(23.23 \%)$ displayed systemic reactions after bee sting.

Analysis of the blood group distribution among the sensitized patients to wasp and bee venom and controls isshown in Tables 1-4, where the difference among the distribution between the cases and controls was not statistically significant in blood groups.

Analysis of blood group distribution among the patients with wasp allergy and control revealed no association (Tab.1-2; $\mathrm{p}=0.12$ ). Similar results were observed in patients with bee venom allergy (Tab. $3-4 ; \mathrm{p}=0.42$ ). Analysis of the blood groups distribution among all sensitized patients to Hymenoptera venom and controls is shown in Table 5, where the difference among the distribution between the cases and controls was also not statistically significant $(\mathrm{p}=0.11)$.

Table 1. Comparison of $\mathrm{ABO}$ blood groups and $\mathrm{Rh}$ factor positive between patients sensitized to vespids venom.

\begin{tabular}{lccccc}
\hline A $, \mathrm{B}, \mathrm{AB}, 0$ & \multicolumn{2}{c}{ Patients with sensitivity to vespids venom } & \multicolumn{2}{c}{ Control Group } \\
\cline { 2 - 6 } groups Rh positive & $\mathrm{n}$ & $\%$ & Age (average, sd) & $\mathrm{n}$ & $\%$ \\
\hline A Rh (+) & 78 & 35.45 & $42.14 \pm 14.25$ & 21600 & 38.16 \\
\hline B Rh (+) & 59 & 26.81 & $43.95 \pm 14.92$ & 11505 & 20.32 \\
\hline AB Rh (+) & 16 & 7.27 & $42.06 \pm 15.17$ & 4380 & 7.737 \\
\hline O Rh (+) & 67 & 30.45 & $46.51 \pm 13.50$ & 19122 & 33.78 \\
\hline Total & 220 & 100 & $43.5 \pm 1.91$ & 56607 & 100 \\
\hline
\end{tabular}

$\mathrm{P}$-Value -0.18 . The result is not significant at $\mathrm{p}<0.05$

Table 2. Comparison of $A B O$ blood groups and Rh factor negative between patients sensitized to vespids venom.

\begin{tabular}{lccccc}
\hline A, B, AB, 0 & \multicolumn{3}{c}{ Patients with sensitivity to vespids venom } & \multicolumn{2}{c}{ Control Group } \\
\cline { 2 - 7 } groups Rh negative & $\mathrm{n}$ & $\%$ & Age (average, sd) & $\mathrm{n}$ & $\%$ \\
\hline A Rh (-) & 12 & 23.51 & $43.42 \pm 9,74$ & 5457 & 37.68 \\
\hline B Rh (-) & 10 & 19.61 & $42.2 \pm 13,93$ & 2916 & 20.14 \\
\hline AB Rh (-) & 5 & 9.80 & $44.6 \pm 13,74$ & 1097 & 7.57 \\
\hline O Rh (-) & 24 & 47.06 & $47.29 \pm 16,4$ & 5011 & 34.60 \\
\hline Total & 51 & 100 & $44.25 \pm 2,22$ & 14481 & 100 \\
\hline
\end{tabular}

The result is not significant at $p<0.05$

Table 3. Comparison of ABO blood groups and Rh factor positive between patients sensitized to apides venom.

\begin{tabular}{lccccc}
\hline A $, \mathrm{B}, \mathrm{AB}, 0$ & \multicolumn{3}{c}{ Patients with sensitivity to apids venom } & \multicolumn{2}{c}{ Control Group } \\
\cline { 2 - 6 } groups Rh positive & $\mathrm{N}$ & $\%$ & Age (average, sd) & $\mathrm{n}$ & $\%$ \\
\hline A Rh (+) & 30 & 45.45 & $40.53 \pm 14.14$ & 21600 & 38.16 \\
\hline B Rh (+) & 8 & 12.12 & $44.75 \pm 10.91$ & 11505 & 20.32 \\
\hline AB Rh (+) & 7 & 10.61 & $48.71 \pm 15.54$ & 4380 & 7.737 \\
\hline O Rh (+) & 21 & 31.82 & $46.57 \pm 18.16$ & 19122 & 33.78 \\
\hline Total & 66 & 100 & $45 \pm 3.74$ & 56607 & 100
\end{tabular}

The result is not significant at $\mathrm{p}<0.05$
Table 4. Comparison of $A B O$ blood groups and Rh factor negative between patients sensitized to apides venom

\begin{tabular}{lccccc}
\hline A, B, AB, & \multicolumn{3}{c}{ Patients with sensitivity to apids venom } & \multicolumn{2}{c}{ Control Group } \\
\cline { 2 - 6 } groups Rh negative & $\mathrm{N}$ & $\%$ & Age (average, sd) & $\mathrm{n}$ & $\%$ \\
\hline A Rh (-) & 7 & 43.75 & $51.85 \pm 16.80$ & 5457 & 37.68 \\
\hline B Rh (-) & 5 & 31.25 & $46 \pm 12$ & 2916 & 20.14 \\
\hline AB Rh (-) & 0 & 0 & 0 & 1097 & 7.57 \\
\hline ORh (-) & 4 & 25 & $59 \pm 9.21$ & 5011 & 34.60 \\
\hline Total & 16 & 100 & $49.33 \pm 7.02$ & 14481 & 100 \\
\hline
\end{tabular}

The result is not significant at $\mathrm{p}<0.05$

Table 5. Distribution of $A B O$ blood groups patients sensitized to Hymenoptera venom and controls.

\begin{tabular}{lccccc}
\hline $\mathrm{A}, \mathrm{B}, \mathrm{AB}, 0$ & \multicolumn{2}{c}{ Patients with sensitivity to Hymenoptera venom } & \multicolumn{2}{c}{ Control Group } \\
\cline { 2 - 6 } groups & $\mathrm{n}$ & $\%$ & Age (average, sd) & $\mathrm{n}$ & $\%$ \\
\hline $\mathrm{A}$ & 127 & 35.98 & $40.53 \pm 14.14$ & 27075 & 38.08 \\
\hline $\mathrm{B}$ & 82 & 23.23 & $44.75 \pm 10.91$ & 14421 & 20.28 \\
\hline $\mathrm{AB}$ & 28 & 7.93 & $48.71 \pm 15.54$ & 5477 & 7.70 \\
\hline 0 & 116 & 32.86 & $46.57 \pm 18.16$ & 24133 & 33.94 \\
\hline Total & 353 & 100 & $45 \pm 3.74$ & 71106 & 100
\end{tabular}

P-Value - 0.1. The result is not significant at $p<0.05$

\section{DISCUSSION}

The presented study is the first to examine the relationship between the $\mathrm{ABO}$ blood group phenotype and anaphylactic reactions after Hymenoptera stings. $\mathrm{ABO}$ and $\mathrm{Rh}$ genes and phenotypes vary widely across races and geographical boundaries, despite the fact that the antigens involved are stable throughout life. The genes that determine glycosyltransferases responsible for the human $\mathrm{ABO}$ blood group are located on chromosome 9 (9q34.1). ABO (glycoproteins) are present in all body cells. The results of this study indicate that that groups $\mathrm{A}$ and $\mathrm{O}$ were predominant. Gene expression with respect to the $\mathrm{ABO}$ system in the current study can be shown with a general formula $A>O>B>A B$. The relationship between different diseases and blood groups were examined in some previous studies. Infections like Crimia-Congo fever, norovirus, influenza A2, adenovirus, Vibrio El Torand hepatitis $\mathrm{C}$ are more prevalent among people with blood group $\mathrm{O}$ [8]. People with blood group $\mathrm{B}$ and $\mathrm{AB}$ are prone to urinary tract infections and less susceptible to Helicobacter pylori. An interesting observation on malaria was shown by Bedu-Addo et al. [9] who reported that blood group $\mathrm{O}$ was associated with protection against malaria. Other studies sought for an association between the ABO blood group and cancer [10,11], which in 1960 clearly demonstrated that pancreatic and gastric cancers are more common in persons of group $\mathrm{A}$ than in persons of groups $\mathrm{O}$ or B. In the epidemiological study by Etemadi [12], non-O blood groups were associated with a significantly increased risk of total death and mortality due to cardiovascular disease.

The association between the $\mathrm{ABO}$ group and allergic disease were also analyzed. Studies on the ABO group system and susceptibility to allergic rhinitis revealed that the $\mathrm{O}$ blood group was associated with allergic rhinitis [13]. The results observed in asthma were discordant. Kauffmann [14] suggested that Lewis-negative or non-secretor with group $\mathrm{O}$ predispose to lower lung function and higher prevalence of 
wheezing and asthma. On the contrary, other publications reported no significant differences between asthma and any blood group in ABO $[15,16]$. Recently performed studies evaluating the relationship between $\mathrm{ABO}$ blood group status and allergic diseases have indicated a strong association with red meat allergy, and the B-negative blood groups after tick bites. The ticks Amblyomma americanum and Ixodes ricinus induce IgE antibodies against carbohydrate galactose- $\alpha-1,3-$ galactose ( $\alpha-\mathrm{Gal})$. Hamsten et al. [17] identified 39 patients with a history of allergic reactions after consumption of mammalian meat and IgE against $\alpha-G a l$.

The current study assumes that systemic anaphylactic reactions caused by Hymmenoptera stings, like other abovementioned insects (Plasmodium falciparum, Amblyomma americanum, Ixodes ricinus) may have an association with $\mathrm{ABO}$ blood groups. Additional presumptions to the presentedr analyzes were discussions in the literature related to the associations of some allergic diseases with ABO groups. The current results obtained unequivocally show that the $\mathrm{ABO}$ blood group phenotype does not affect the anaphylactic reactions after Hymenoptera stings.

\section{CONCLUSIONS}

The obtained results provide no evidence that the ABO blood group influences the risk of severe anaphylactic reactions after hymenoptera stings.

\section{Conflict of interests}

All authors report no conflict of interest relevant to this article.

\section{Author's contributions}

Data was collected by EC. KP and ZB were involved in the analysis and interpretation of data. $\mathrm{KP}$ and $\mathrm{ZB}$ were involved in the drafting of the manuscript, critically revised each draft, and gave their final approval for publication. All authors agree to be accountable for all aspects of this work and have participated sufficiently to take public responsibility for the content. All authors read and approved the final manuscript.

\section{Acknowledgments}

The authors are greatly indebted to Dr Paweł Wojtylak, head of the Regional Centre for Blood Transfusion in Bydgoszcz, for both collecting and contributing the data for this study.

\section{Funding}

The authors declare that no funding was received for the presented study.

\section{Ethics approval}

The study was approved by the Ethical Committee of the L. Rydygier Collegium Medicum, Bydgoszcz / Collegium Medicum, Nicolaus Copernicus University, Toruń, Poland

\section{REFERENCES}

1. Bilò BM, Bonifazi F. Epidemiology of insect-venom anaphylaxis. Curr Opin Allergy ClinImmunol. 2008; 8(4): 330-337.

2. Pałgan K. Postępowanie diagnostyczne i terapeutyczne u pacjentów uczulonych na jad owadów błonkoskrzydłych. Alergol. Pol. 2014: (1); 60-64

3. Ruëff F, Vos B, Oude Elberink J, Bender A, Chatelain R, Dugas-Breit S, Horny HP, Küchenhoff H, Linhardt A, Mastnik S, Sotlar K, Stretz E, Vollrath R, Przybilla B, Flaig M. Predictors of clinical effectiveness of Hymenoptera venom immunotherapy. Clin Exp Allergy. 2014;44(5): 736-46.

4. Przybilla B, Ruëff F. Insect stings: clinical features and management. DtschArztebl Int. 2012;109 (13): 238-248.

5. Farhud D D, Yeganeh Z M. A brief history of human blood groups. Iran J Pub Health, 2013: 42(1); 1-6.

6. Franchini M, Bonfanti C. Evolutionary aspects of ABOblood group in humans. Clin Chim Acta. 2015; 444: 66-71.

7. Ring J, Messmer K. Incidence and severity of anaphylactoid reactions to colloid volume substitutes. Lancet1977; 1: 466-469.

8. Mohsenpour B, Hajibagheri K, Afrasiabian S, Ghaderi E, Ghasembegloo $\mathrm{S}$. ABO blood groups and susceptibility to brucellosis. Jpn J Infect Dis. 2015; 68(2): 124-127.

9. Bedu-Addo G, Gai P P, Meese S, Eggelte T A, Thangaraj K, Mockenhaupt F P. Reduced prevalence of placental malaria in primiparae with blood group O. Malar J. 2014; 13: 289.

10. Aird I, Lee DR, Roberts IA. ABO blood groups and cancer of oesophagus, cancer of pancreas, and pituitary adenoma. Br Med J. 1960;1:1163-1166.

11. Franchini M, Lippi G. The intriguing relationship between the ABO blood group, cardiovascular disease, and cancer. BMC Med. 2015 Jan 16;13:7. doi: 10.1186/s12916-014-0250-y.

12. Etemadi A, Kamangar F, Islami F, Poustchi H, Poursham A, Brennan P, Boffetta P, Malekzadeh R, Dawsey SM, Abnet CC, Emadi A. Mortality and cancer in relation to $\mathrm{ABO}$ blood group phenotypes in the Golestan Cohort Study. BMC Medicine. 2014. doi:10.1186/s12916-014-0237-8

13. See comment in PubMed Commons belowFalsarella N, da Costa Ferreira A L, Nakashima F, de Cássia C, de Mattos B, de Mattos L C. Evidence of an association between the $\mathrm{O}$ blood group and allergic rhinitis. Rev Bras HematolHemoter. 2011; 33(6): 444-448.

14. Kauffmann F, Frette C, Pham QT, Nafissi S, Bertrand J P, Oriol R. Associations of blood group-related antigens to FEV1, wheezing, and asthma. American Journal of Respiratory and Critical Care Medicine1996; 153:1, 76-8

15. Denborough MA, Downing HJ. Secretor status in asthma and hay fever. J Med Genet. 1968; 5(4): 302-305.

16. Bijanzadeh M, Ramachandra NB, Mahesh PA, Savitha MR, Manjunath BS, Jayaraj BS. Lack of association between asthma and ABO blood group. Lung. 2009; 187(6): 389-392.

17. Hamsten C, Tran TAT, Starkhammar M, Brauner A, Commins SP, Platts-Mills T AE, van Hage M. Red meat allergy in Sweden: Association with tick sensitization and B-negative blood groups. J Allergy Clin Immunol, 2013; 132(6), 1431-1434. 